\title{
Quality of Life and Associated Factors in Indonesian Diabetic Patients with Foot Ulcers
}

\author{
Yunita Sari ${ }^{1}$, Iwan Purnawan ${ }^{1}$, Annas Sumeru ${ }^{1}$, Agis Taufik ${ }^{1}$ \\ ${ }^{l}$ Department of Nursing, Jenderal Soedirman University, Indonesia \\ Corresponding Author: Yunita Sari (yunita.unsoed@gmail.com)
}

\begin{abstract}
Background: Diabetic foot ulcer will cause a reduction in quality of life (QOL), high care burden, and even mortality. An assessment of QOL and associated factors in patients with diabetic foot ulcer is important to provide evidence for establishing a care plan program for such patients. However, up to the present, there is no evidence of a published study that investigates the QOL and its associated factors in patients with diabetic foot ulcer in Indonesia.

Purpose: The purpose of this study was to investigate the QOL in patients with diabetic foot ulcer in each domain and investigate the factors associated with this condition.

Methods: The design of this study was a cross-sectional study. The total sample for this study was 55 patients. The QOL data were collected using a Diabetic Foot Ulcer Scale questionnaire. Statistical analyses were conducted using Mann-Whitney U-test and Kruskal-Wallis test.

Results: The result showed that the QOL in the domains of emotions, positive compliance, family life, and friend were high, while the QOL in the domains of daily activities, physical health, leisure, finances, positive attitude, and treatment ranged from low to average. Significant differences were found between income $(p=0.004)$, grade of the wound $(p=0.047)$, number of wounds $(p=0.029)$, and blood glucose $(p=0.013)$ with QOL of patients. Other variables did not have a significant relationship with QOL, but marital status had a significant correlation with the domain of leisure $(p=0.004)$ and duration of the ulcer had a significant correlation with the domain of emotions $(p=0.001)$

Conclusion: There is a correlation between income, grade of the wound, the number of wounds, and blood glucose with QOL of patients with a diabetic foot ulcer. This study recommends to take into account economic status, grade and number of wound, and blood glucose level in order to improve the QOL of patients for an effective patient care plan.
\end{abstract}

Keywords: Diabetic; foot ulcer; quality of life

\section{BACKGROUND}

Diabetes mellitus (DM) is a chronic disease that has become a global problem since its number is rapidly increasing. In 1980, 108 million people were diagnosed with DM, which increased to 422 million in 2014 (Deshpande, Harris-Hayes, \& Schootman, 2008). It is predicted that there will be 592 million people with DM worldwide ( 1 in 10 
persons) by 2035 (Leon \& Maddox, 2015). The number of DM patients in Indonesia is also increasing. A previous study reported that the number of diabetic people in Indonesia reached 8.4 million in 1995, which then doubled in 2006. Indonesia was even included in the top ten countries with the largest number of DM patients (Shaw, Sicree, \& Zimmet, 2010).

The increase in patients with DM will consequently increase the number of people with DM complications. One of the most severe complications associated with DM is diabetic foot ulcer. Previous studies reported that $15 \%$ of patients with DM would develop a foot ulcer during their lifetime (Mathur et al., 2017). Diabetic foot ulcer was also a causative factor for amputation. A previous study reported that $85 \%$ of lower limb amputations in the US are due to diabetic foot ulcer (Driver, Fabbi, Lavery, \& Gibbons, 2010). A study by Yusuf et al. (2016) reported a prevalence of diabetic foot ulcer in Sulawesi of $12 \%$. This number is higher compared to other countries, even China, which has only a prevalence of about 5.9\% (Yusuf et al., 2016). Sulawesi's prevalence might be higher since many cases of diabetic foot ulcer in Indonesia have been unreported. Moreover, several previous studies showed that many patients of DM in Indonesia are at risk of developing foot ulcers due to the lack of knowledge with regard to diet management for DM patients (Aklima, Kritpracha, \& Thaniwattananon, 2012, 2013; Primanda, Kritpracha, \& Thaniwattananon, 2011)

Previous studies reported that diabetic foot ulcer could reduce the mobility of patients (Al-Rubeaan et al., 2015; Tuttolomondo, Maida, \& Pinto, 2015). The loss of mobility will affect the activities and everyday tasks of patients. This consequence has been reported to cause depression and increase budget, resulting in a reduction of QOL (de Jesus Pereira et al., 2014; Gilpin \& Lagan, 2008; Salome, Blanes, \& Ferreira, 2011). The presence of diabetic foot ulcer also affects the economic condition of patients. A previous study reported that about $50 \%$ of patients with diabetic foot ulcer lost their job due to their condition. The loss of job will diminish their self-esteem, especially for younger patients. Other studies showed that patients with diabetic foot ulcer feel more anger, frustration, depression, and powerlessness than diabetic patients without foot ulcer (de Jesus Pereira et al., 2014; Gilpin \& Lagan, 2008). From these previous studies, it can be concluded that diabetic foot ulcer causes a reduction of QOL.

Unfortunately, most studies about the QOL of patients with diabetic foot ulcer were conducted in developed countries (Macioch et al., 2017; Prazeres \& Figueiredo, 2014; Spanos et al., 2017). Until now, studies about QOL in patients with foot ulcer conducted in developing countries are very limited, and no studies exist that investigated the associated factors of QOL in patients with diabetic foot ulcer in Indonesia. A previous study reported that the difference in the region would affect many aspects of QOL (Sekhar, Thomas, Unnikrishnan, Vijayanarayana, \& Rodrigues, 2015). The study about QOL in diabetic patients have been widely conducted in Indonesia, however up to present, the study about QOL in patients with diabetic foot ulcer in Indonesia is very few, and no study investigates the associated factors of QOL in patients with diabetic foot ulcer in Indonesia. Previous studies showed that patients with diabetic foot ulcers had significantly much poorer QOL compared with diabetic patients without foot ulcers (Almeida, Silviera, Santo, Pereira, \& Salome, 2013; Ribu, Hanestad, Moum, Birkeland, 
\& Rustoen, 2007). Another previous study also showed that patients with diabetic foot ulcer had significantly lower QOL in all domains of QOL (Almeida et al., 2013). Based on the previous studies, it can be concluded that the QOL in diabetic patients with foot ulcer is different with QOL in diabetic patients without foot ulcer.

A previous study by Syarif investigated the QOL in patients with diabetic foot ulcers in Serang, Indonesia (Syarif, 2013). His study showed that $57.6 \%$ of all patients with diabetic foot ulcer have low QOL. His study also showed that both the physical and environmental domains were low while the social and psychological domains were high. The study by Syarif (2013) only investigated the QOL of patients; however, the factors associated with QOL in patients with diabetic foot ulcer in Indonesia had not been studied yet. Moreover, his study only investigated three domains of QOL. Other previous studies revealed that the domains of QOL in patients with diabetic foot ulcer consisted of 11 domains including the domains of leisure activities, physical health, daily activities, emotions, noncompliance, family life, friends, foot and wound treatment, satisfaction toward medical care, positive attitude, and financial ability (Macioch et al., 2017; Prazeres \& Figueiredo, 2014; Spanos et al., 2017). The assessment of the QOL and its associated factors is important for nurses since a previous study revealed that $85 \%$ of amputations were due to complication from diabetic foot ulcer and low QOL (Gilpin \& Lagan, 2008). Such an assessment can be used as evidence for the best intervention program for patients with a diabetic foot ulcer. Therefore, it is needed to investigate the QOL in each domain and the factors associated with QOL in patients with diabetic foot ulcer in Indonesia. This study is the first study to investigate the associated factors of QOL of patients with diabetic foot ulcer in Indonesia.

\section{PURPOSE}

This study aimed to investigate the QOL for each domain and the factors associated with QOL in diabetic patients with foot ulcer in Indonesia.

\section{METHODS}

This study was conducted as a cross-sectional study, and a total of 55 patients were included in this study. The sampling method was purposive sampling. Patients attending two wound care centers and one hospital in Purwokerto, from January to August 2017, were consecutively recruited by the nurses.

The inclusion criteria of this study were the patients with a diabetic foot ulcer and older than 35 years. The exclusion criteria were patients with cardiovascular and pulmonary problems; patients with ulcers from causes other than diabetic ulcers, such as malignant ulcer or wound due to the accident; patients who were illiterate or patients who could not complete the questionnaire due to cognitive deficit, such as those with dementia or mental confusion.

Before participating in the study, all diabetic patients with foot ulcers who met inclusion and exclusion criteria were informed of the reason and the aim of the study. Patients were also informed of their right to decline for participating in this study. All patients who agreed to participate were given a consent form to participate. The identities of 
patients were also kept confidential. The ethical approval of this study was obtained from the ethical committee of the Faculty of Medicine, Jenderal Soedirman University, Purwokerto, Indonesia.

The severity of the foot ulcers was classified according to the classification of MeggittWagner (Wagner, 1981). The wounds were classified as follows; grade 1: ulcer involves epidermis and dermis layer/superficial layer, grade 2: ulcer extends to deep layer of skin without abscess or osteomyelitis, grade 3: ulcer extends to deep layer of skin with abscess, and osteomyelitis, grade 4: a localized gangrene in portion of toes, forefoot or heel, grade 5: extensive gangrenous involves all the part of foot (Wagner, 1981).

The data about QOL were collected using the diabetic foot ulcer scale (DFS). The DFS was designed by Johnson and Johnson (ICOM Health Economics, US). The DFS questionnaire is an instrument, which was designed to assess the domain of QOL in diabetic patients with foot ulcers. The original DFS consists of 11 domains with a total of 58 items. The domains include the domain of daily activities, physical health, leisure activities, emotions, family life, noncompliance, friends, foot and wound treatment, satisfaction toward medical care, positive attitude, and financial ability (Abetz, Sutton, Brady, McNulty, \& Gagnon, 2002).

The scoring method of DFS scale used five optional Likert scales. The DFS scores were calculated based on the sum of all items related to a particular domain. In each item, value 1 indicates the worst QOL, and value 5 indicates the best QOL. All of the DFS scales were scored from 0 to 100, with higher scores indicating better QOL (Abetz et al., 2002; Bann et al., 2003; Vymětalová \& Zeleníková, 2016).

The DFS has been tested in various languages (Abetz et al., 2002). The result showed that DFS has high validity and reliability. The questionnaire has been translated into Indonesian and was then back-translated. The result of the validity test showed that all domains were valid, except for the domain of satisfaction. Therefore, the total domains after validity test were ten domains. The result of the reliability showed a Cronbach's coefficient alpha of 0,761 (Abetz et al., 2002; Bann et al., 2003; Vymětalová \& Zeleníková, 2016).

Data analyses were performed using SPSS. Descriptive data were analyzed by using means, percentage, and standard deviation. After the normality of the data was analyzed, nonparametric tests such as Mann-Whitney U-test and Kruskal-Wallis test were used.

\section{RESULTS}

\section{The demographic profile of respondents}

The distribution of samples according to their age, education, employment status, gender, marital status, income, smoking, and type of treatment is shown in Table 1. Table 1 shows that most patients were at the age of 56-65 years (49.1\%), had a background of secondary high school (38.2\%), were employed (54.5\%), were female $(65.5 \%)$, were married $(92.7 \%)$, had low income $(43.6 \%)$, had normal body mass of index $(67.3 \%)$, did not smoke $(94.5 \%)$, and received oral diabetes treatment (63.6\%). 
Table 1. Demographic data of respondents

\begin{tabular}{|c|c|c|}
\hline Variables & $\mathrm{f}$ & $\%$ \\
\hline \multicolumn{3}{|l|}{ Age } \\
\hline $36-45$ & 1 & 1.8 \\
\hline $46-55$ & 13 & 23.6 \\
\hline $56-65$ & 27 & 49.1 \\
\hline Above 65 & 14 & 25.5 \\
\hline \multicolumn{3}{|l|}{ Education } \\
\hline No education & 3 & 5.5 \\
\hline Secondary School & 21 & 38.2 \\
\hline Junior High School & 8 & 14.5 \\
\hline Senior High School & 12 & 21.8 \\
\hline Bachelor & 11 & 20 \\
\hline \multicolumn{3}{|l|}{ Employment status } \\
\hline Housewife & 14 & 25.5 \\
\hline Employed & 30 & 54.5 \\
\hline Unemployed & 5 & 9.1 \\
\hline Retired & 6 & 10.9 \\
\hline \multicolumn{3}{|l|}{ Gender } \\
\hline Male & 19 & 34.5 \\
\hline Female & 36 & 65.5 \\
\hline \multicolumn{3}{|l|}{ Marital Status } \\
\hline Married & 51 & 92.7 \\
\hline Single & 1 & 1.8 \\
\hline Widowed & 2 & 3.6 \\
\hline \multicolumn{3}{|l|}{ Income } \\
\hline High & 20 & 36.4 \\
\hline Moderate & 11 & 20 \\
\hline Low & 24 & 43.6 \\
\hline \multicolumn{3}{|l|}{ Body mass index } \\
\hline Slim & 2 & 3.6 \\
\hline Normal & 37 & 67.3 \\
\hline Excess weight & 16 & 29.1 \\
\hline \multicolumn{3}{|l|}{ Smoking } \\
\hline Yes & 3 & 5.5 \\
\hline No & 52 & 94.5 \\
\hline \multicolumn{3}{|l|}{ Type of treatment } \\
\hline No Medication & 4 & 7.3 \\
\hline Insulin & 16 & 29.1 \\
\hline Oral & 35 & 63.6 \\
\hline
\end{tabular}




\section{Characteristic of wounds}

The wound characteristics such as grade of the wound, number of ulcers, and duration of ulcers are shown in Table 2. Related with the grade, most of the patients were in grade $2(60 \%)$, and had one ulcer $(72.7 \%)$. Related with the duration of ulcers, most of the ulcer had been present for less than six months $(87.3 \%)$.

Table 2. Characteristics of wounds

\begin{tabular}{lrc}
\hline Variables & $\mathrm{f}$ & $\%$ \\
\hline Grade of wound & 7 & 12.7 \\
$\quad$ Grade 1 & 33 & 60 \\
Grade 2 & 11 & 20 \\
Grade 3 & 4 & 7.3 \\
$\quad$ Grade 4 & & \\
Number of ulcers & 40 & 72.7 \\
$\quad$ One & 11 & 20 \\
Two & 4 & 7.3 \\
Three & & \\
Duration of ulcer & 48 & 87.3 \\
$\quad$ Less than six months & 4 & 7.3 \\
Six months to one year & 3 & 5.5 \\
$\quad$ More than one year & & \\
\hline
\end{tabular}

\section{Quality of life of patients and associated factors}

The data related to the QOL of patients in each domain with a diabetic foot ulcer is shown in Table 3. The mean scores for the DFS domains ranged from 40 in the domain of positive attitude to 89 in the domain of emotions. The domains of positive attitude, treatment, and daily activities had a mean score below 50, while the domains of leisure, physical health, financial, friends, noncompliance, family life, and emotions had a mean score above 50.

The data about factor associated with QOL and factor associated with each domain of QOL are shown in Table 4. There were significant differences between income $(p=0.004)$, grade of the wound $(p=0.047)$, number of the wound $(p=0.029)$, and blood glucose $(p=0.013)$ with QOL of patients. Although the QOL of other factors were not correlated with the QOL, the marital status has a significant correlation with the domain of leisure $(p=0.004)$, and the duration of ulcer had a significant correlation with emotions $(p=0.001)$.

Table 3. Domains of QOL in patients with diabetic foot ulcer

\begin{tabular}{lcc}
\hline \multicolumn{1}{c}{ Domain of QOL } & Mean & SD \\
\hline Leisure & 54 & 29.6 \\
Physical health & 56 & 9.5 \\
Daily activities & 47 & 26 \\
Emotions & 89 & 14 \\
Noncompliance & 80 & 25 \\
Family life & 80 & 16 \\
\hline
\end{tabular}




\begin{tabular}{lll}
\hline \multicolumn{1}{c}{ Domain of QOL } & Mean & $S D$ \\
\hline Friends & 79 & 16 \\
Treatment & 46.5 & 26.3 \\
Positive attitude & 40 & 26.3 \\
Financial & 6 & 17 \\
\hline
\end{tabular}

\section{DISCUSSION}

The finding showed that the domains of emotions, noncompliance, family life, and friends were high. The mean domain of emotion in this study was 89. In this study, the mean score of the emotion domain was higher compared to previous studies (Valensi, Girod, Baron, Moreau-Defarges, \& Guillon, 2005; Vymětalová \& Zeleníková, 2016). This result is surprising since the previous studies were conducted in France (Valensi et al., 2005) and in Czech (Vymětalová \& Zeleníková, 2016), which are considered as developed countries. It had been considered that the QOL in a developed country should be better than a developing country, such as Indonesia. The domain of emotion reflects the evaluation of emotional status due to foot problems, indicating that Indonesian people, in this study, could adapt to the presence of the foot ulcer.

The positive compliance in this study also has a high score. Noncompliance scale in DFS consisted of healthy behaviors (diet) and medical compliance. The high score of positive compliance in this study means that patients have more attention to manage the diet when there is foot ulcer than when patients did not have a foot ulcer. In addition, patients are also more compliant with medical advice related to her/his condition. The value of positive compliance in this study was higher than that in a previous study by Valensi et al. (2005). Based on previous studies, several factors can affect the compliance of the patients, such as severity of the condition, physical difficulties due to illness, and cost of treatment (Jin et al., 2008). These factors might be the reason why the positive compliance in this study is higher than in the previous study. In our study, most of the patients have grade 2 and 3 of diabetic foot ulcer, while in the study Valensi et al. (2005), most of the patients have grade 1 of diabetic foot ulcer. The more severe condition in our study might lead to more physical difficulties and higher cost of treatment, and therefore, the compliance with medical advice is higher.

On the other hand, the domains of daily activities, physical health, leisure, financial, positive attitude, and treatment domain had low to average QOL. Previous studies have reported that the presence of diabetic foot ulcer will affect the activity of daily living, physical health, social and family life, as well as partake in leisure activities (Bouhassira, Letanoux, \& Hartemann, 2013; Gilpin \& Lagan, 2008; Steel, Reece, \& Daw, 2016). A previous study showed that foot ulcer significantly affected the person ability to perform daily activities (Gilpin \& Lagan, 2008). The loss of the ability to move will affect patients in their activities and everyday tasks (Gilpin \& Lagan, 2008). The loss of mobility also causes pressure in the working life of patients since patients cannot easily perform tasks in the workplace. Such inability of free movement will eventually cause anger, depression, powerlessness, and, an increased budget for treatment, resulting in a reduction of QOL (de Jesus Pereira et al., 2014; Steel et al., 2016). In this study, the QOL for the subdomains of positive attitude and treatment were also average. Positive attitude and treatment domains contain the patients' ability to 
manage the wound and to take care of their foot. The lower positive attitude and treatment in this study might be due to the low educational background. Thus, the knowledge of patients on how to manage the wound and to take measures to prevent the wound from occurring is low.

The result of this study indicated a significant relationship between QOL and income. This result is in agreement with a previous study that reported that diabetic foot ulcer also affects finances. Studies showed that people with diabetic foot ulcer face financial difficulties, indicating that $50 \%$ of patients with diabetic foot ulcer lost their work due to foot ulcers, and the remaining 50\% reported that their career prospects were limited (Gilpin \& Lagan, 2008). The lack of finances and employment will finally cause a feeling of insignificance and a sense of loss.

A significant relationship between QOL and the grade of the wound, number of wounds, and blood glucose level in this study might be caused by an effect of diabetic foot ulcer that can cause limitation of daily activities, causing of increase of financial and other dependence on the family. The grade of the wound and the number of wounds affected the QOL since a severe wound will take time longer to treat than a superficial wound, and the increased number of wounds will also cause the family or the nurse to require more time to treat the single wound. Both longer healing time and increased number of wounds will cause an increase a budget for treatment. The result of this study is supported by previous studies by Gonzalez de la Torre, Quintana-Lorenzo, PerdomoPerez, \& Verdu (2017) and Valensi et al. (2005) which reported that the number of ulcers and severity of chronic wound would affect QOL of patients.

In this study, the blood glucose also affects the QOL. This study is the first study to report that blood glucose level can affect the QOL of patients with a diabetic foot ulcer. The previous study revealed that blood glucose level would cause a reduction of QOL in patients with DM, but the effect of blood glucose level in the QOL of patients with diabetic foot ulcer is not investigated yet. The decrease of QOL due to high blood glucose in patients with diabetic foot ulcer might because high blood glucose will cause the wound to deteriorate into more severe foot ulcer. A previous study by Santos, Carvalho, Souza, \& Albuquerque (2015) showed that high blood glucose would cause deterioration of wound to a more severe ulcer, and finally lead to foot amputation.

Although no significant difference was found between marital status and QOL in this study, a significant relationship was found between the domain of leisure with marital status and the duration of the ulcer with emotions. This might indicate that the presence of a spouse will enable diabetic patients with foot ulcer to relax and to participate in activities. This finding is in accordance with a previous study, reporting that a person who lives alone will feel lonely and more insecure (de Jesus Pereira et al., 2014). The duration of ulcer that will cause negative emotions might be due to the increase in the financial burden since patients or family has to treat the wound for a long time.

This study has some limitations. This study was conducted with small sample size. Variation in QOL between regions in Indonesia might occur. Next study using a large sample size is needed. In our study, we excluded all patients who had cardiovascular 
and pulmonary problems and patients who had an amputation above the toes. However, we did not exclude other comorbidities such as nephropathy and retinopathy since these comorbidities are usually present in patients with diabetes mellitus. However, in our study, we used questionnaires of QOL which is specific for foot ulcer in each domain and therefore eliminating the responses from other causes other than due to foot ulcers. This study also had strengths that were worth to note. This study has high originality since it is the first study to assess the QOL in diabetic foot ulcer in Indonesia. In addition, we also use DFS scale which was specifically designed to assess QOL in relation to diabetic foot ulcer, instead of general QOL scales which are not specific for a diabetic foot ulcer. In this study, we also found that DFS which was translated into Indonesian showed high validity and reliability, and therefore suitable for assessing QOL in diabetic foot ulcer in Indonesia.

\section{CONCLUSION}

The study showed that QOL of patients with a diabetic ulcer in the domains of emotions, noncompliance, family life, and a friend were high, while the domains of daily activities, physical health, leisure, financial, positive attitude, and treatment domain were low. The factors that are associated with QOL in diabetic foot ulcer patients in Indonesia are income, grade of the wound, the number of the wound, and blood glucose. This study provides very important evidence for a clinical setting. The evidence obtained in this study could be used as data for nurses to provide the best preventive care that can improve QOL of patients with a diabetic foot ulcer. It is essential to consider factors such as income, grade of the ulcer, number of ulcer, and blood glucose level when making the care plan for patients.

\section{REFERENCES}

Abetz, L., Sutton, M., Brady, L., McNulty, P., \& Gagnon, D. D. (2002). The diabetic foot ulcer scale (DFS): a quality of life instrument for use in clinical trials. Practical Diabetes International, 19(6), 167-175. https://doi.org/10.1002/pdi.356

Aklima, A., Kritpracha, C., \& Thaniwattananon, P. (2012). Development of familybased dietary self-management support program on dietary behaviors in patients with type 2 diabetes mellitus in Indonesia: A literature review. Nurse Media Journal of Nursing, 2,(2). Retrieved from https://ejournal.undip.ac.id/index.php/medianers/article/view/3969

Aklima, A., Kritpracha, C., \& Thaniwattananon, P. (2013). Dietary behaviors among patients with type 2 diabetes mellitus in Indonesia. Nurse Media Journal of Nursing, 3(1). https://doi.org/10.14710/nmjn.v3i1.4453

Al-Rubeaan, K., Al Derwish, M., Ouizi, S., Youssef, A. M., Subhani, S. N., Ibrahim, H. M., \& Alamri, B. N. (2015). Diabetic foot complications and their risk factors from a large retrospective cohort study. PloS One, 10(5), e0124446. https://doi.org/10.1371/journal.pone.0124446

Almeida, S.A., Silveira, M. M., Santo, P.F.E., Pereira, R.C., \& Salomé, G M. (2013). Assessment of the quality of life of patients with diabetes mellitus and foot ulcers. Rev Bras Cir Plást, 28(1), 142-146.

Bann, C. M., Fehnel, S. E., \& Gagnon, D. D. (2003). Development and validation of the diabetic foot ulcer scale-short form (DFS-SF). PharmacoEconomics, 21(17), 1277-1290. 
Bouhassira, D., Letanoux, M., \& Hartemann, A. (2013). Chronic pain with neuropathic characteristics in diabetic patients: a French cross-sectional study. PloS One, 8(9), e74195. https://doi.org/10.1371/journal.pone.0074195

de Jesus Pereira, M. T., Magela S. G., Guimaraes O. D., Cunha E. V. H., Almeida, S.A., \& Masako F. L. (2014). Feelings of powerlessness in patients with diabetic foot ulcers. Wounds : A Compendium of Clinical Research and Practice, 26(6), 172177.

Deshpande, A.D., Harris-Hayes, M., \& Schootman, M. (2008). Epidemiology of diabetes and diabetes-related complications. Physical Therapy, 88(11), 12541264. https://doi.org/10.2522/ptj.20080020

Driver, V. R., Fabbi, M., Lavery, L.A., \& Gibbons, G. (2010). The costs of diabetic foot: the economic case for the limb salvage team. Journal of Vascular Surgery, 52(3 Suppl), 17S-22S. https://doi.org/10.1016/j.jvs.2010.06.003

Gilpin, H., \& Lagan, K. (2008). Quality of life aspects associated with diabetic foot ulcers : A review. The Diabetic Foot Journal, 11(2), 56-62.

Gonzalez de la Torre, H., Quintana-Lorenzo, M. L., Perdomo-Perez, E., \& Verdu, J. (2017). Correlation between health-related quality of life and venous leg ulcer's severity and characteristics: a cross-sectional study. International Wound Journal, 14(2), 360-368. https://doi.org/10.1111/iwj.12610

Jin, J., Sklar, G.E., Oh, V.M.S., Li, S.C. (2008). Factors affecting therapeutic compliance: a review from the patient's perspective. Therapeutics and Clinical Risk Management, 4(1). 269-286.

Leon, B.M., \& Maddox, T.M. (2015). Diabetes and cardiovascular disease: Epidemiology, biological mechanisms, treatment recommendations and future research. World Journal of Diabetes, 6(13), 1246-1258. https://doi.org/10.4239/wjd.v6.i13.1246

Macioch, T., Sobol, E., Krakowiecki, A., Mrozikiewicz-Rakowska, B., Kasprowicz, M., \& Hermanowski, T. (2017). Health-related quality of life in patients with diabetic foot ulceration - translation and Polish adaptation of diabetic foot ulcer scale-short form. Health and Quality of Life Outcomes, 15(1), 15. https://doi.org/10.1186/s12955-017-0587-y

Mathur, R. K., Sahu, K., Saraf, S., Patheja, P., Khan, F., \& Gupta, P. K. (2017). Lowlevel laser therapy as an adjunct to conventional therapy in the treatment of diabetic foot ulcers. Lasers in Medical Science, 32(2), 275-282. https://doi.org/10.1007/s10103-016-2109-2

Prazeres, F., \& Figueiredo, D. (2014). Measuring quality of life of old type 2 diabetic patients in primary care in Portugal: a cross-sectional study. Journal of Diabetes and Metabolic Disorders, 13, 68. https://doi.org/10.1186/2251-6581-13-68

Primanda, Y., Kritpracha, C., \& Thaniwattananon, P. (2011). Dietary behaviors among patients with type 2 diabetes mellitus in Yogyakarta, Indonesia. Nurse Media Journal of Nursing, 1(2). Retrieved from https://ejournal.undip.ac.id/index.php/medianers/article/view/975 
Ribu, L., Hanestad, B.R., Moum, T., Birkeland, K., \& Rustoen, T. (2007). A comparison of the health-related quality of life in patients with diabetic foot ulcers, with a diabetes group and a nondiabetes group from the general population. Quality of Life Research: An International Journal of Quality of Life Aspects of Treatment, Care and Rehabilitation, 16(2), 179-189. https://doi.org/10.1007/s11136-006-0031-y

Salome, G.M., Blanes, L., \& Ferreira, L.M. (2011). Assessment of depressive symptoms in people with diabetes mellitus and foot ulcers. Revista Do Colegio Brasileiro de Cirurgioes, 38(5), 327-333.

Santos, I.C.R.V., Carvalho, E. F., Souza, W. V., \& Albuquerque, E. C. (2015). Factors associated with diabetic foot amputations . Jornal Vascular Brasileiro, 14(1). 3745. http://dx.doi.org/10.1590/1677-5449.20140049

Sekhar, M. S., Thomas, R. R., Unnikrishnan, M. K., Vijayanarayana, K., \& Rodrigues, G. S. (2015). Impact of diabetic foot ulcer on health-related quality of life: a cross-sectional study. Seminars in Vascular Surgery, 28(3), 165-171. https://doi.org/https://doi.org/10.1053/j.semvascsurg.2015.12.001

Shaw, J. E., Sicree, R. A., \& Zimmet, P. Z. (2010). Global estimates of the prevalence of diabetes for 2010 and 2030. Diabetes Research and Clinical Practice, 87(1), 414. https://doi.org/10.1016/j.diabres.2009.10.007

Spanos, K., Saleptsis, V., Athanasoulas, A., Karathanos, C., Bargiota, A., Chan, P., \& Giannoukas, A. D. (2017). Factors associated with ulcer healing and quality of life in patients with diabetic foot ulcer. Angiology, 68(3), 242-250. https://doi.org/10.1177/0003319716651166

Steel, A., Reece, J., \& Daw, A.M. (2016). Understanding the relationship between depression and diabetic foot ulcers. Journal of Social Health and Diabetes, 4(1), 17-24. https://doi.org/10.4103/2321-0656.164792

Syarif, H. (2013). Kualitas hidup pasien ulkus diabetes di poliklinik endokrin RSUD, Banda Aceh [The quality of life of patients with diabetic ulcers in endocrine polyclinic in RSUD Banda Aceh]. Idea Nursing Journal, IV(1), 1-7.

Tuttolomondo, A., Maida, C., \& Pinto, A. (2015). Diabetic foot syndrome as a possible cardiovascular marker in diabetic patients. Journal of Diabetes Research, 2015, 268390. https://doi.org/10.1155/2015/268390

Valensi, P., Girod, I., Baron, F., Moreau-Defarges, T., \& Guillon, P. (2005). Quality of life and clinical correlates in patients with diabetic foot ulcers. Diabetes \& Metabolism, 31(3 Pt 1), 263-271.

Vymětalová, R., \& Zeleníková, R. (2016). Painful ulceration and QOL of patients with the diabetic foot syndrome. Cent Eur J Nurs Midw, 7(4), 512-517. https://doi.org/10.15452/CEJNM.2016.07.0023

Wagner, F. W. J. (1981). The dysvascular foot: a system for diagnosis and treatment. Foot \& Ankle, 2(2), 64-122.

Yusuf, S., Okuwa, M., Irwan, M., Rassa, S., Laitung, B., Thalib, A., ... Sugama, J. (2016). Prevalence and risk factor of diabetic foot ulcers in a regional hospital, Eastern Indonesia. Open Journal of Nursing, 6(January), 1-10. https://doi.org/10.4236/ojn.2016.61001 
Table 4. Association of demographic data and characteristics of the wound on QOL and its domains

\begin{tabular}{|c|c|c|c|c|c|c|c|c|c|c|c|}
\hline \multirow{2}{*}{$\begin{array}{c}\text { Demographic and } \\
\text { wound characteristics }\end{array}$} & \multirow{2}{*}{$\begin{array}{l}\text { Quality } \\
\text { of life }\end{array}$} & \multicolumn{10}{|c|}{ Domain } \\
\hline & & Leisure & $\begin{array}{c}\text { Physical } \\
\text { health }\end{array}$ & $\begin{array}{c}\text { Daily } \\
\text { activities } \\
\end{array}$ & Emotion & $\begin{array}{c}\text { Positive } \\
\text { compliance }\end{array}$ & Family & Friends & Treatment & $\begin{array}{l}\text { Positive } \\
\text { Attitude }\end{array}$ & Financial \\
\hline Age & 0.106 & 0.158 & 0.146 & 0.157 & 0.323 & 0.731 & 0.357 & 0.395 & 0.475 & 0.114 & 0.426 \\
\hline Gender & 0.552 & 0.55 & 0.288 & 0.687 & 0.881 & 0.969 & 0.888 & 0.245 & 0.833 & 0.678 & 0.622 \\
\hline Education & 0.266 & 0.147 & 0.528 & 0.283 & 0.604 & 0.261 & 0.592 & 0.444 & 0.835 & 0.812 & 0.179 \\
\hline Job & 0.624 & 0.635 & 0.45 & 0.993 & 0.621 & 0.836 & 0.28 & 0.939 & 0.865 & 0.344 & 0.582 \\
\hline Income & $0.004^{*}$ & 0.305 & $0.02 *$ & $0.003^{*}$ & 0.82 & 0.326 & 0.055 & 0.246 & $0.02 *$ & 0.074 & 0.209 \\
\hline Marital status & 0.687 & $0.004 *$ & 0.848 & 0.56 & 0.489 & 0.342 & 0.536 & 0.931 & 0.13 & $0.018^{*}$ & 0.324 \\
\hline Grade of wound & $0.047 *$ & 0.395 & $0.01 *$ & $0.011^{*}$ & 0.421 & $0.029 *$ & $0.022 *$ & 0.228 & $0.005^{*}$ & 0.087 & 0.4 \\
\hline Duration of wound & 0.155 & 0.228 & 0.713 & 0.529 & $0.001 *$ & 0.943 & 0.733 & 0.143 & 0.205 & 0.45 & 0.111 \\
\hline Number of wound & $0.029 *$ & 0.164 & 0.064 & $0.024 *$ & 0.692 & $0.015^{*}$ & $0.005^{*}$ & $0.019 *$ & 0.099 & 0.111 & 0.616 \\
\hline Blood glucose level & $0.013^{*}$ & $0.022 *$ & $0.014^{*}$ & $0.024^{*}$ & 0.843 & 0.790 & $0.009 *$ & 0.083 & 0.056 & 0.348 & 0.147 \\
\hline Smoking & 0.687 & 0.931 & 0.687 & 0.467 & 0.793 & 0.61 & 0.256 & 0.489 & 0.766 & 0.661 & 0.61 \\
\hline History of Wound & 0.097 & 0.499 & 0.014 & 0.106 & 0.819 & 0.808 & 0.18 & 0.296 & 0.082 & 0.679 & 0.439 \\
\hline BMI & 0.902 & 0.813 & 0.141 & 0.917 & 0.132 & 0.827 & 0.491 & 0.937 & 0.252 & 0.214 & 0.814 \\
\hline Type of treatment & 0.063 & 0.168 & 0.232 & 0.036 & 0.716 & 0.423 & 0.08 & 0.978 & 0.021 & 0.242 & 0.104 \\
\hline
\end{tabular}

$* p<0.05$ (Mann-Whitney U-test and Kruskal-Wallis test) 